\title{
Descrição histológica do escroto de caprinos nativos do Estado do Piauí, segundo o grau de bipartição escrotal
}

\author{
Scrotum histological description in native goats from Piaui State, according to \\ scrotal bipartition level
}

\author{
Aline Soares Nunes ${ }^{I}$ Miguel Ferreira Cavalcante FilhoII \\ Antonio Augusto Nascimento Machado Júnior ${ }^{\text {III }}$ Ana Lúcia Abreu-Silva ${ }^{\text {IV }}$ \\ Airton Mendes Conde JúniorV José Adalmir Torres Souza ${ }^{\mathrm{VI}}$ Maria Acelina Martins Carvalho ${ }^{\mathrm{II}}$
}

\section{RESUMO}

Esta pesquisa teve por objetivo avaliar as características histológicas do escroto de caprinos com diferentes graus de divisão escrotal. Foram utilizados 15 caprinos distribuídos em três grupos (GI, escroto não bipartido; GII, escroto bipartido até $50 \%$ do comprimento testicular; $e$ GIII, escroto bipartido superior a 50\% do cumprimento do testículo). Fragmentos do escroto foram submetidos a processamento histológico e analisados em microscópio de luz. Na pele do escroto, a epiderme apresentava-se composta por epitélio pavimentoso estratificado queratinizado, organizado nos estratos basal, espinhoso, granuloso e córneo. Sua espessura, independentemente da divisão escrotal, aumentou gradativamente da região proximal à distal, sendo mais espessa nos caprinos do GIII $(68,91 \mu \mathrm{m})$ e mais fina na região da rafe escrotal do grupo GI. A derme apresentava-se escassa em tecido adiposo e possuía uma maior quantidade de glândulas sudoríparas apócrinas nos animais do GIII $\left(18,12 G S \mathrm{~mm}^{-2}\right)$, quando comparado com os do GI $(16,14 G S$ $\left.\mathrm{mm}^{-2}\right)$ e GII $\left(14,82 \mathrm{GS} \mathrm{mm}^{-2}\right)$. Com relação às glândulas sebáceas, não foi encontrada diferença numérica significativa entre os animais pesquisados. Concluiu-se que os caprinos que apresentam bipartição escrotal mais acentuada (GIII) podem apresentar uma maior produção de suor, pois contém maior quantidade de glândulas sudoriparas no escroto, fato que pode favorecer a perda de calor por evaporação, colaborando no processo de termorregulação testicular.

Palavras-chave: pequeno ruminante, pele escrotal, histologia, glândula sudorípara.

\begin{abstract}
Among male goats in tropical regions, a bipartition in scrotum happens frequently Studies have shown that goats with bigger accented division in scrotum have reproductive advantages in relation to those that had not presented this characteristic, giving them a better thermoregulation for testis in the animals with bipartite scrotum. This research aimed to evaluate histological characteristics of the scrotum, in 15 goats, distributed in three groups, according to scrotal configuration (GI, unique scrotum; GII, scrotum bipartite up to $50 \%$ of the testicular length; GIII, scrotum bipartite upper than 50\%). It was removed fragments of the organ and they were processed, according to histological routine and analyzed in light microscope. The scrotum skin is constituted of epidermis and dermis, and the epidermis is formed by stratified keratinizing epithelium, organized in basale, spinosum, granulosum, and corneum stratums. The epidermis width, independent of the scrotum configuration, increased gradually from the proximal to the distal region, being wider (average $=68,91 \mu \mathrm{m}$ ) in GIII's animals. In the medial region of bipartite scrotum the epidermis showed to be thinner than on the raphe in animals of unique scrotum. The dermis, rare in fat tissue, showed a greater quantity of sweat apocrine glands in the animal of GIII, average of $18,12 G S \mathrm{~mm}^{-2}$, while in the GI's, 16,14GS $\mathrm{mm}^{-2}$ and GII, $14,82 \mathrm{GS} \mathrm{mm} \mathrm{mm}^{-2}$, suggesting a greater production of sweat that could favor the lost of heat by evaporation. About the number of sebaceous glands, there was no statistic difference among the groups.
\end{abstract}

Key words: small ruminant, scrotal histology, skin, sweat glands.

${ }^{\text {I} C e n t r o ~ d e ~ C i e ̂ n c i a s ~ A g r a ́ r i a s, ~ U n i v e r s i d a d e ~ F e d e r a l ~ d o ~ P i a u i ́ ~(U F P I), ~ T e r e s i n a, ~ P I, ~ B r a s i l . ~}$

IIDepartamento de Morfofisiologia Veterinária, Centro de Ciências Agrárias (CCA), UFPI, 64049-550, Teresina, PI, Brasil. Email: carvalhomam@uol.com.br.*Autor para correspondência.

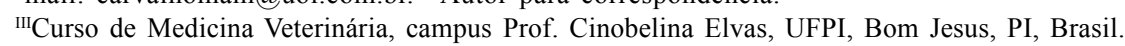

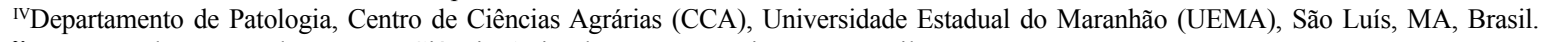

vPrograma de Pós-graduação em Ciência Animal, UFPI, Teresina, PI, Brasil.

${ }^{\mathrm{VI}}$ Departamento de Clínica e Cirurgia Veterinária, CCA, UFPI, Teresina, PI, Brasil. 


\section{INTRODUÇÃO}

O escroto é um divertículo abdominal que tem como funções proteger os testículos e colaborar com o mecanismo de termorregulação por meio do seu fluxo sanguíneo, de trocas calóricas e da sudorese (KASTELIC et al., 2000). Nos pequenos ruminantes, o escroto é longo e penduloso, podendo ultrapassar o nível das articulações tíbio-társicas, sendo sua pele abundantemente recoberta por pelos. A pele escrotal é delgada, flexível e intimamente aderida à túnica dartos (GETTY, 1986; GODINHO etal., 2001; DYCE etal., 2004).

A epiderme apresenta uma espessura variável, sendo formada por epitélio pavimentoso estratificado e queratinizado, composto dos estratos germinativo, espinhoso, granuloso, lúcido e córneo (DELLMAN \& BROWN, 1982; BANKS, 1992; GARTNER \& HIATT, 1993; SCHALLER, 1999; FRANDSON et al., 2003). As glândulas sebáceas encontram-se localizadas em uma região formada pelo folículo piloso, pela superfície da pele e pelo músculo eretor do pêlo, e seus ductos desembocam no interior dos folículos pilosos (FRANDSON et al., 2003). Sua secreção oleosa, além de lubrificar e impermeabilizar a pele e a pelagem, também favorece a disseminação do suor e retarda o crescimento bacteriano (DYCE et al., 2004).

As glândulas sudoríparas, sob uma visão geral, podem ser distinguidas em dois tipos, as apócrinas, que eliminam suor nos folículos pilosos, e as écrinas, que secretam diretamente na superfície da pele. As glândulas apócrinas são as mais predominantes e sua secreção é importante no metabolismo salino e na regulação da temperatura. Já as glândulas écrinas desempenham um papel menor, atuando somente na regulação da temperatura (DYCE et al., 2004).

Na pele do escroto, as glândulas sebáceas e as glândulas sudoríparas apócrinas diferem quanto ao tamanho e número, nas várias espécies de mamíferos domésticos (DELLMAN \& BROWN, 1982). Em bovinos, o volume e a área das glândulas sudoríparas, por unidade de área superficial de pele, são maiores no escroto do que na pele de outras áreas do corpo. Com a elevação da temperatura ambiente, o escroto se distende, diminuindo a espessura da pele, e, com isso, aproximando os testículos das glândulas sudoríparas, as quais atuam diminuindo a temperatura desse órgão por meio da sudorese (BLAZQUEZ et al., 1988).

As glândulas sudoríparas escrotais são maiores e produzem mais suor que as de qualquer outra parte do corpo, conforme BOHÓRQUES MAHECHA \& GODINHO (1992). Tais glândulas podem produzir cinco vezes mais suor do que as da pele de outras regiões, em resposta a uma elevação da temperatura ambiental (ROBERTSHAW \& VERCOE, 1980). A perda de calor por evaporação da água da pele está diretamente relacionada com a extensão das glândulas sudoríparas (KOLB, 1987).

Fatores ambientais, atuando sobre os animais, podem induzir o aparecimento de adaptações para facilitar sua sobrevivência e reprodução. Um exemplo de adaptação observada principalmente em caprinos é a bipartição escrotal. Essa característica é relatada principalmente em animais criados em locais próximos à linha do equador, em regiões de clima quente (ROBERTSHAW, 1982; NUNES et al., 1984). Segundo relatos da literatura (NUNES et al., 1983, SILVA et al., 1986), a bipartição escrotal aumenta a superfície do escroto e testículo em contato com o meio ambiente, fato que contribui para uma melhor dissipação de calor. ALMEIDA et al. (2008) afirmaram que existe um maior número de ramos arteriais na região da bipartição escrotal quando comparada com a região da rafe escrotal nos animais sem escroto bipartido. Esses aspectos podem colaborar para o aumento de parâmetros reprodutivos, pois facilitam termorregulação testicular e a espermatogênese nesse grupo de animais (MACHADO JUNIOR et al., 2008). Desse modo, VIEIRA et al. (2008) sugerem que, em locais que apresentam clima quente, os caprinos com escroto bipartido devem ser priorizados para reprodução, pois apresentam sêmen de melhor qualidade.

Diante da importância do escroto para termorregulação testicular e da ausência de informação sobre a influência da separação externa do escroto de caprinos na morfologia desse órgão, realizou-se este trabalho que teve por objetivo avaliar os aspectos histológicos da pele escrotal, por meio da análise estrutural da pele e quantificação das glândulas sudoríparas e sebáceas em caprinos com escroto bipartido e não bipartido.

\section{MATERIAIS E MÉTODOS}

Foram utilizados 15 escrotos coletados de caprinos nativos com idade entre 12 e 36 meses, divididos segundo a configuração escrotal (GI animais com escroto sem bipartição; GII - caprinos com bipartição escrotal até $50 \%$ do comprimento testicular; e GIII - animais com bipartição escrotal superior a $50 \%$ do comprimento dos testículos). O experimento foi conduzido na Universidade Federal do Piauí, Centro de Ciências Agrárias, na cidade de Teresina, com latitude: $05^{\circ} 05^{\prime} 21^{\prime}$ 'sul, longitude: $42^{\circ} 48^{\prime} 07$ ' oeste, altitude: $72 \mathrm{~m}$, radiação solar mensal: 
$676 \mathrm{cal} \mathrm{cm}^{-2} \mathrm{dia}^{-1}$, temperatura média: $27,3^{\circ} \mathrm{C}$, umidade relativa do ar $-70 \%$, clima tropical (Aw), com chuvas principalmente no verão e outono.

Foram coletados fragmentos transversais de pele, com aproximadamente $1 \mathrm{~cm}^{2}$, dos terços proximal, médio, distal das faces cranial, caudal e medial (nos animais com escroto bipartido) ou da rafe escrotal (nos animais sem escroto bipartido), para fixação em formaldeído a $10 \%$, por 48 horas. Em seguida, os fragmentos foram submetidos ao processamento histológico, cortados a $5 \mu \mathrm{m}$ de espessura, corados pelo método hematoxilina - eosina e analisados em microscópio de luz. Para a mensuração da espessura da epiderme, foi utilizada uma escala milimétrica (cada unidade $=0,125 \mathrm{~mm})$ acoplada à ocular $(10 \mathrm{x}) \mathrm{em}$ microscópio de luz, em um aumento total de 400x. Os resultados foram divididos pelo aumento $(400 \mathrm{x})$, para se obter o valor real, e multiplicados por 1000 , para transformá-los em micrômetro $(\mu \mathrm{m})$.

A quantificação das glândulas sudoríparas foi realizada com auxílio de um sistema com linhas de inclusão e exclusão de $1 \mathrm{~cm}^{2}$ de área, acoplado à ocular (10x), em um aumento total de 50x, correspondendo a $0,2 \mathrm{~mm}$ no fragmento. Os resultados obtidos em cinco locais de cada fragmento foram somados, para se obter o número de glândulas por milímetro quadrado $\left(\mathrm{mm}^{2}\right)$ no fragmento.

O delineamento experimental foi inteiramente ao acaso, em esquema fatorial 3x3x3, três grupos (G I, G II e G III), três locais (proximal, médio, distal) e três faces (cranial, caudal e medial ou rafe escrotal), com cinco repetições. Os dados foram submetidos à análise de variância, e as médias foram comparadas pelo teste de Student-Newman-Keuls (SNK), com nível de significância de 5\%.

\section{RESULTADOS E DISCUSSÃO}

A pele do escroto dos caprinos pesquisados apresentava-se constituída por epiderme e derme, contendo glândulas sudoríparas e sebáceas (Figura1A). A epiderme, independente da configuração escrotal, mostrava-se composta por epitélio pavimentoso estratificado queratinizado, constituído pelo estrato basal, com células cilíndricas organizadas em uma única camada, moldada à camada papilar da derme; o estrato espinhoso, bastante reduzido no terço proximal do escroto, apresentava várias camadas de células

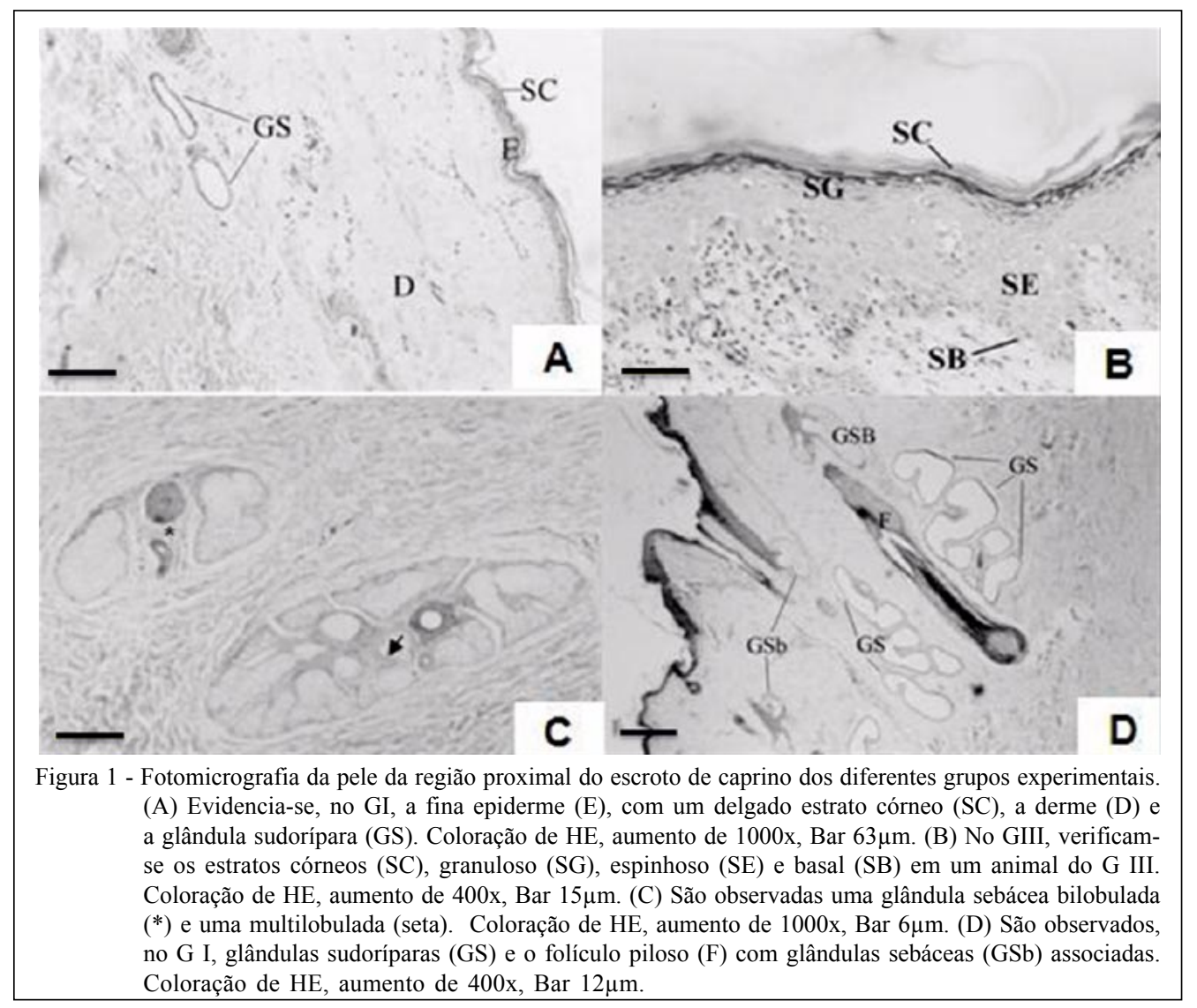

Ciência Rural, v.40, n.,8 ago, 2010. 
poliédricas mais achatadas que as do estrato basal; o estrato granuloso continha células achatadas, com citoplasma rico em grânulos e núcleo de difícil observação; e externamente o estrato córneo era bastante reduzido, como uma delgada fita, formada por células mortas e queratinizadas (Figura1B).

Não foram encontradas diferenças em relação à literatura consultada que abordavam características da pele em outras espécies domésticas (DELLMAN \& BROWN, 1982; BANKS, 1992; GARTNER \& HIATT, 1993; SCHALLER, 1999). Neste estudo não foi observada a presença do estrato lúdico, à semelhança do relatado por BANKS(1992), que afirma ser esse estrato observado somente nas regiões epidérmicas muito espessas do corpo.

A espessura da epiderme do escroto de caprinos, independentemente da configuração escrotal, aumentava gradativamente da região proximal à distal, a exemplo do observado na literatura (BANKS, 1992). A derme, nos animais estudados, apresentava-se constituída de tecido conjuntivo frouxo com pouca presença de tecido adiposo e composta por duas camadas: a camada papilar, com a rede capilar responsável pela nutrição da epiderme; e a camada reticular, com glândulas cutâneas (Figuras 1A, B e C), à semelhança do descrito para outros animais (DELLMAN \& BROWN, 1982; BANKS, 1992; GARTNER \& HIATT, 1993; SCHALLER, 1999).

As glândulas sudoríparas do escroto de caprinos dos diferentes grupos apresentavam-se como estruturas alveolares simples e enoveladas do tipo apócrina em número de uma ou duas por folículo, com seus ductos excretores formados por uma única camada de células cúbicas e desembocando nos folículos pilosos (Figura 1D), tal como observado na literatura (KOLB, 1987; BANKS, 1992; GARTNER \& HIATT, 1993; REECE, 2006). Na superfície luminal dessas glândulas, foram encontrados glomérulos ou vesículas, que, segundo BANKS (1992), é um indicativo do mecanismo de secreção apócrina.

As médias referentes à morfometria da epiderme e quantificação das glândulas cutâneas encontram-se nas tabelas 1 e 2 . A espessura da epiderme variou estatisticamente $(\mathrm{P}<0,05)$ entre os grupos, com os caprinos do G III apresentando a maior média $(68,91 \mu \mathrm{m})$, seguidos pelos animais do G I $(55,82 \mu \mathrm{m})$ e G II $(46,97 \mu \mathrm{m})$. Comparando os valores médios por região, observou-se um aumento gradativo da região proximal $(29,33 \mu \mathrm{m})$ à distal $(99,90 \mu \mathrm{m})$. No terço distal da rafe escrotal, os caprinos com escroto não bipartido apresentaram a espessura da epiderme maior $(82,50 \mu \mathrm{m})$ que a observada nos animais do G II $(48,75 \mu \mathrm{m})$ e G III $(38,75 \mu \mathrm{m})$ (Tabela 1$)$. Tal variação
Tabela 1 - Médias da espessura da epiderme (em micrômetros) em diferentes regiões do escroto de caprinos do grupo I - escroto não bipartido; grupo II - escroto com bipartição até $50 \%$ do comprimento testicular; e grupo III - escroto com bipartição superior a $50 \%$ do comprimento testicular. Teresina-PI.

\begin{tabular}{|c|c|c|c|}
\hline \multirow{2}{*}{ Regiões $^{1}$} & \multicolumn{3}{|c|}{-----------Grupos²'----------- } \\
\hline & I & II & III \\
\hline Proximal & $29,4^{\mathrm{Ac}}$ & $26,5^{\mathrm{Ac}}$ & $32,2^{\mathrm{Ac}}$ \\
\hline Média & $49,7^{\mathrm{Ab}}$ & $35,9^{\mathrm{Bc}}$ & $55,5^{\mathrm{Ac}}$ \\
\hline Distal & $89,4^{\mathrm{Ba}}$ & $74,7^{\mathrm{Ba}}$ & $135,6^{\mathrm{Aa}}$ \\
\hline $\begin{array}{l}\text { Rafe escrotal distal/área } \\
\text { medial }\end{array}$ & $82,5^{\mathrm{Aa}}$ & $48,7^{\mathrm{Bb}}$ & $38,7^{\mathrm{Bc}}$ \\
\hline Rafe escrotal proximal & $28,1^{\mathrm{Cc}}$ & $48,9^{\mathrm{Bc}}$ & $82,5^{\mathrm{Ab}}$ \\
\hline Médias $^{1}$ & $55,8^{\mathrm{B}}$ & $46,9^{\mathrm{C}}$ & $68,9^{\mathrm{A}}$ \\
\hline
\end{tabular}

${ }^{1}$ Regiões de coleta dos fragmentos da pele do escroto.

${ }^{2}$ Grupos experimentais: I - grupo de caprinos sem bipartição; II caprinos com bipartição escrotal de até $50 \%$; III - grupo de caprinos com bipartição escrotal superior a 50\%.

Médias seguidas por mesma letra maiúscula na mesma linha não apresentam diferença significativa pelo Teste SNK $(\mathrm{P}>0,05)$.

Médias seguidas por mesmas letras minúsculas na mesma coluna não apresentam diferença significativa pelo Teste SNK $(\mathrm{P}>0,05)$.

atribui-se ao fato de a região medial do escroto nos animais com bipartição escrotal ser uma área mais protegida e, portanto, menos suscetível à traumas, fato não observado para a região da rafe, que é mais exposta.

No que se refere à quantidade das glândulas sudoríparas, foi constatada diferença estatisticamente significante $(\mathrm{P}<0,05)$ entre os grupos. Os caprinos do GIII apresentavam maior média geral de glândulas $\left(18,12 \mathrm{GS} \mathrm{mm}^{-2}\right)$, seguidos pelos animais do GI $(16,14 \mathrm{GS}$ $\left.\mathrm{mm}^{-2}\right)$ e GII $\left(14,82 \mathrm{GS} \mathrm{mm} \mathrm{mm}^{-2}\right)$. O terço distal foi o local onde essas glândulas foram observadas em maior número $\left(19,77 \mathrm{GS} \mathrm{mm}^{-2}\right)$, seguido pelo terço proximal $\left(18,67 \mathrm{GS} \mathrm{mm}^{-2}\right)$ e pelo distal $\left(16,53 \mathrm{GS} \mathrm{mm}^{-2}\right)$ da rafe escrotal, do terço médio $\left(14,07 \mathrm{GS} \mathrm{mm}^{-2}\right)$ e da proximal $\left(12,77 \mathrm{GS} \mathrm{mm}^{-2}\right)$ do escroto (Tabela 2). A média da face cranial $\left(17,33 \mathrm{GS} \mathrm{mm}^{-2}\right)$ foi estatisticamente $(\mathrm{P}<0,05)$ maior que a da caudal $\left(15,38 \mathrm{GS} \mathrm{mm}^{-2}\right)$. O número de glândulas sudoríparas encontradas nos animais do GIII foi superior ao encontrado na literatura para caprinos (ROBERTSHAW, 1982), bovinos (REECE, 2006) e búfalos (SAPATRA et al., 2005). Esse fato pode possibilitar aos caprinos com escroto bipartido uma maior perda de calor por transpiração, reduzindo a temperatura do escroto e testículo e favorecendo o processo espermatogênico e a posterior qualidade do sêmen. Essa inferência é corroborada por VIEIRA et al. (2008), os quais observaram que os caprinos com escroto bipartido, mesmo em temperatura mais elevadas, conseguiam manter uma qualidade espermática melhor do que os animais com escroto sem bipartição. 
Tabela 2 - Médias do número de glândulas sudoríparas por $\mathrm{mm}^{2}$ (GS $\mathrm{mm}^{-2}$ ) em diferentes regiões do escroto de caprinos do grupo I - escroto não bipartido; grupo II escroto com bipartição até $50 \%$ do comprimento testicular; e grupo III - escroto com bipartição superior a $50 \%$ do comprimento testicular. Teresina-PI.

\begin{tabular}{|c|c|c|c|}
\hline \multirow{2}{*}{ Regiões $^{1}$} & \multicolumn{3}{|c|}{----------Grupos ${ }^{2}$---------- } \\
\hline & I & II & III \\
\hline Proximal & $12^{\mathrm{Bb}}$ & $11,4^{\mathrm{Bc}}$ & $14,9^{\mathrm{Ab}}$ \\
\hline Média & $12,3^{\mathrm{Bb}}$ & $12,9^{\mathrm{Bc}}$ & $17^{\mathrm{Ab}}$ \\
\hline Distal & $20^{\mathrm{ABa}}$ & $16,8^{\mathrm{Bb}}$ & $22,5^{\mathrm{Aa}}$ \\
\hline $\begin{array}{l}\text { Rafe escrotal distal/ área } \\
\text { medial }\end{array}$ & $22,3^{\mathrm{Aa}}$ & $13^{\mathrm{Bc}}$ & $14,3^{\mathrm{Bb}}$ \\
\hline Rafe escrotal proximal & $14,1^{\mathrm{Bb}}$ & $20^{\mathrm{Aa}}$ & $21^{\mathrm{Aa}}$ \\
\hline Médias $^{1}$ & $16,1^{\mathrm{B}}$ & $14,8^{\mathrm{B}}$ & $18,1^{\mathrm{A}}$ \\
\hline
\end{tabular}

${ }^{1}$ Regiões de coleta dos fragmentos da pele do escroto

${ }^{2}$ Grupos experimentais: I - grupo de caprinos sem bipartição; II caprinos com bipartição escrotal de até $50 \%$; III - grupo de caprinos com bipartição escrotal superior a 50\%.

Médias seguidas por mesma letra maiúscula na mesma linha não apresentam diferença significativa pelo Teste SNK $(\mathrm{P}>0,05)$.

Médias seguidas por mesmas letras minúsculas na mesma coluna não apresentam diferença significativa pelo Teste SNK $(\mathrm{P}>0,05)$.

\section{CONCLUSÃO}

Os caprinos portadores de bipartição escrotal apresentaram epiderme mais espessa e um maior número de glândulas sudoríparas. Esses achados indicaram uma maior produção de suor, com consequente sistema termorregulador escroto testicular mais eficiente.

\section{REFERÊNCIAS}

ALMEIDA, M.M. et al. Efeito do grau de bipartição escrotal sobre a vascularização arterial do escroto de caprinos nativos do Estado do Piauí. Brazilian Journal of Veterinary Research and Animal Science, v.45, n.3, p.167-173, 2008. Disponível em: <http://www.revistasusp.sibi.usp.br/scielo.php?pid=S1413$95962008000300001 \&$ script $=$ sci_arttext $>$. Acesso em: 29 jun. 2010 .

BANKS, W.J. Histologia veterinária aplicada. 2.ed. São Paulo: Manole, 1992. 658p.

BLAZ QUEZ, N.B. et al. Sweat glands of the scrotum of the bull. Journal of Reproduction and Fertility v.83, p.673674, 1988. Disponível em: <http://www.ncbi.nlm.nih.gov/ pubmed/3411557?dopt=Citation $>$. Acesso em: 29 jun. 2010.

BOHÓRQUES MAHECHA, G.A.; GODINHO, H.P. Irrigação arterial do escroto de zebu, Bos indicus. Arquivo Brasileiro de Medicina Veterinária e Zootecnia, v.44, n.2, p.121$127,1992$.

DELLMAN, H.D.; BROWN, E.M. Histologia veterinária. Rio de Janeiro: Guanabara-Koogan, 1982. 397p.
DYCE, K.M. et al. Tratado de anatomia veterinária. 3.ed. Rio de Janeiro: Guanabara-Koogan, 2004. 811p.

FRANDSON, R.D. et al. Anatomia e fisiologia dos animais domésticos. 6.ed. Rio de Janeiro: Guanabara-Koogan. 2003. $454 \mathrm{p}$.

GARTNER, L.P.; HIATT, J.L. Atlas de histologia. Rio de janeiro: Guanabara-Koogan, 1993. 322p.

GETTY, R. Anatomia dos animais domésticos. Sisson/ Grossman. 5.ed. Rio de Janeiro: Guanabara-Koogan, 1986. V.1, $1134 \mathrm{p}$.

GODINHO, H.P. et al. Anatomia dos ruminantes domésticos. Belo Horizonte: Instituto de Ciências Biológicas da UFMG (Departamento de Morfologia), 2001. 415p.

JACINTO, M.A.C. et al. Características anátomo-estruturais da pele de ovinos (Ovis áries L.) lanados e deslanados de diferentes idades. In: REUNIÃO ANUAL DA SOCIEDADE BRASILEIRA DE ZOOTECNIA, 1998, Fortaleza, CE. Anais... Fortaleza: Sociedade Brasileira de Zootecnia, 1998. p.532-534.

KASTELIC, J.P. et al. Scrotal/testicular thermoregulation in bulls. In: ____. Topics in bull fertility. Publisher: Internacional Veterinary Information Service. Disponível em: $<$ http://www.ivis.org $>$. Online. Acesso em: 21 jun. 2000..

KOLB E. Fisiologia veterinária. 4.ed. Rio de Janeiro: Guanabara-Koogan, 1987. 636p.

MACHADO JÚNIOR, A.A.N. et al. Cellular characterization and quantification of seminiferous ephitelium in goats with and without bipatition of the scrotum. Brazilian Journal of Mophological Science, v.25, n.1-4, p.45-45, 2008. Disponível em: <http://jms.org.br/v25n1-4/41>. Acesso em: 29 jun. 2010.

NUNES, J.F. et al. Características espermáticas de caprinos moxotó de acordo com a morfologia escrotal. Sobral: EMBRAPA/CNPCaprinos, 1983. 11p. (Circular técnica, $6)$.

NUNES, J.F. et al. Preliminary report on observed differences in goat semen characteristics based on scroat morphology. In: REUNION INTERNACIONALE DE REPRODUCTION DES RUMINANTS EN ZONE TROPICAL, 20., 1983, Guadelupe. Procedings... Paris: INRA, 1984. p.251-264.

REECE, W.O. Dukes fisiologia dos animais domésticos. 12.ed. Rio de Janeiro: Guanabara-Koogan, 2006. 925p.

ROBERTSHAW, D. Concepts in animal adaptation: thermoregulation of the goat. In: INTERNATIONAL BONFERENCE ON GOAT PRODUCTION AND DISEASE, 3., 1982, Tucson. Proceedings... Seoltsdale: Dairy goat journal, 1982. p.395-397.

ROBERTSHAW, D.; VERCOE, J.E. Scrotal thermoregulation of the bull. Australian Journal Agriculture Research, v.31, p.401-407, 1980. Disponível em: <http://www.publish.csiro.au/ nid/40/paper/AR9800401.htm>. Acesso em: 29 jun. 2010.

Ciência Rural, v.40, n.,8 ago, 2010. 
SAPATRA, R.A. et al. Avaliação das diferenças entre temperatura retal, escrotal e intratesticular e da qualidade de glândulas sudoríparas e sebáceas em escroto de búfalos (Bubalus bubalis) de duas faixas etárias. Revista Brasileira de Reprodução Animal, v.28, n.4, p.202-205, 2005. Disponível em: <http://www.cbra.org.br/pages/publicacoes/rbra/download/ v28n4.pdf $>$. Acesso em: 29 jun. 2010.

SILVA, A.E.D.F. et al. Influência da morfologia escrotal nas características do sêmen e seus efeitos na fertilidade de caprinos. A Hora Veterinária, v.5, n.29, p.66-69, 1986
SCHALLER, O. Nomenclatura anatômica veterinária ilustrada. São Paulo: Manole, 1999. 614p.

VIEIRA, R.J. et al. Influência da morfologia escrotal e da época do ano na qualidade do sêmen de caprinos criados no Estado do Piauí. Revista Brasileira de Ciências Agrárias, v.3, n.4, p.376-380, 2008. Disponível em: <http:// www.agraria.pro.br/sistema/index.php?journal=agraria\&page $=$ issue \&op=view\&path\%5B\%5D=15>. Acesso em: 29 jun. 2010. 